\title{
DEVELOPING AND TESTING A SUITE OF INSTITUTIONAL INDICES TO UNDERPIN THE MEASUREMENT AND MANAGEMENT OF TOURISM DESTINATION TRANSFORMATION
}

\author{
CHAR-LEE J. MCLENNAN,* BRENT D. MOYLE,$\dagger$ \\ LISA M. RUHANEN, + AND BRENT W. RITCHIE $\dagger$ Centre of Leisure and Work, School of Tourism and Hospitality Management, Southern Cross University, Gold Coast, Australia $\$$ School of Tourism, University of Queensland, Brisbane, Australia \\ *Centre for Tourism, Sport and Services Research, Griffith University, Gold Coast, Australia
}

\begin{abstract}
Economic, social, and environmental transformation of destinations as a consequence of tourism has been observed and studied extensively within the tourism literature. Transformation theory has evolved as a tool for understanding structural economic, social, or environmental change, which is driven by institutions. There is an emerging body of research that has sought to identify the institutional aspects of the tourism transformation process. Despite this, there has been limited development of tools that can measure institutions, inhibiting the development of long-run decision-making models that governments can use when developing policies for tourism destination development. As a result this research contributes a suite of institutional indices that can be used by tourism managers and planners to monitor, evaluate, and benchmark the tourism industry's institutions. Drawing from the organizational change literature, the proposed indices focus on competition, management processes, data and research capabilities, collaboration efforts, benchmarking processes, learning ability, and agility and adaptability. This research is an important step in developing combined structural and institutional models that will contribute to the development and implementation of decisionmaking tools to assist destinations seeking to achieve long-term sustainable tourism transformation.
\end{abstract}

Key words: Tourism; Transformation; Businesses; Institutions; Performance measurement; Indices

Introduction

Tourism has emerged as an important economic sector in many countries, often replacing traditional industries such as agriculture. This process of change has been termed "transformation" defined as the long-term process of change, whereby an economy restructures from one economic sector to another owing to institutional change (Seliger, 2002). Institutions are collective 
human-designed actions, and may include government strategies, policies, or laws, business or industry norms, social norms, cultural beliefs, or the general patterns of consumer behavior(Mantzavinos, North, \& Shariq, 2004). Institutions are commonly proposed as important underlying factors in tourism development (Mwangi, 2006).

While transformation theory has been emerging as a key paradigm in tourism research (McLennan, Ruhanen, Ritchie, \& Pham, 2012; Pavlovich, 2003), a number of gaps remain within the transformation literature. In particular, there is limited understanding surrounding the dynamic interaction between structure and institutions, an issue that has been exacerbated by a lack of tools to measure the nuances of institutions. This lack of research foci has limited the development of long-run decisionmaking tools available to governments, resulting in difficulties when developing policies for tourism development (Dwyer et al., 2008).

Institutions are important underlying factors in tourism development and have been identified as requiring further research (Saarinen, 2004). Recognizing that decision making is an important variable in influencing destination change, a number of tourism researchers have suggested there is a need to further investigate how institutions, human agency, and strategic intervention impact on tourism development (Agarwal, 2002; Scott, 2003). The development of institutions in a region is congruous with system learning, which is a process of continually developing rules or beliefs that impact on or guide a system (Schianetz, Kavanagh, \& Lockington, 2007).

It is often argued that government deregulation, intervention, and institutional development are required to overcome the issues and problems of transformation and to stimulate tourism development (Alipour \& Kilic, 2004; Kotlinski, 2004). The literature also suggests that for destinations to undergo successful tourism transformation they require effective tourism policy and few deterrents to visitation, as well as ongoing education, training, research, development, and performance measurement (Briedenhann \& Butts, 2004), indicating a need for ongoing system learning. Existing indicators used to measure institutions in a tourism destination are currently underdeveloped (McLennan et al., 2012).
Given these identified gaps, this research develops a series of institutional indices to measure and benchmark the current institutions of tourism related businesses and government organizations. These indices address competition, management processes, performance measurement, data and research capabilities, collaboration efforts, benchmarking processes, learning, and agility and adaptability. To achieve the aims of this research, data were collected from business and government organizations and a number of indices were developed from the survey data. This contributes the development of a suite of comprehensive institutional indices, which has been limited in tourism research.

\section{Literature Review}

\section{Measures of Institutions in the Tourism Literature}

A growing segment of tourism literature has argued that change in a tourism system's structure is driven by underlying institutions (Hall, 2004; Schianetz et al., 2007). Scott (2003) suggested that different stages of tourism destination development are not the same, but rather are more complex because of the influence of human agency and argued that this requires further investigation. Existing indicators used to measure institutions in a tourism destination are currently underdeveloped and there is little evidence of how institutions interact with structures across the transformation process (McLennan et al., 2012).

Yet strategic mistakes are often unavoidable and inherent in the learning process (Hallegatte, Ghil, Dumas, \& Hourcade, 2008). System learning theory suggests that a system is able to learn, thereby enabling it to adjust to changes in its environment. The learning process occurs via the modification of institutions to enable stability or more directed change (Argyris \& Schon, 1996). System learning theory has been identified in tourism research and used to explain institutional development within destinations (Farrell \& Twining-Ward, 2004; Schianetz et al., 2007).

A number of case studies have suggested that issues and problems in government institutions are the cause of ineffective and inappropriate tourism development (Alipour \& Kilic, 2004; Sergeyev \& Moscardini, 2006). These issues and problems are often attributed to poor tourism policies (such as 
positioning, coordination, and investment), a lack of government support, a narrow perspective, high levels of corruption, and broad political instability. As a result, some researchers doubt whether positive tourism transformation actually ever occurs (Hall, 2004).

Saarinen (2004) and Saarinen and Kask (2008) construed a tourism destination as a spatial structure that develops through a historical process related to its administrative, economic, and cultural institutions. Saarinen (2004) proposed that two key components form a destination's identity. The first is the "discourse of region" (Saarinen, 2004, p. $167)$ that refers to the tourism image, knowledge, meanings, and natural and cultural features that relate to the destination. Over the course of the transformation process these slowly stereotype, resulting in a loss of differentiation between destinations. This implies that more developed destinations are not as "unique" as those in which tourism has just commenced. The second is the "discourse of development" (Saarinen, 2004, p. 167), which represents the institutions, practices, and larger processes that construct the destination. These institutions relate to the holistic and hierarchical concepts discussed earlier and originate from higher level systems, but interact with and govern the tourism industry.

Other tourism researchers have also recognized the importance of institutions. For example, Cottrell, Vaske, Shen, and Ritter (2007) based their work on the prism of sustainability, thus including economic, social, environmental, and institutional dimensions. Shen and Cottrell (2008) developed measures of the four sustainability dimensions based on three to five survey items. They also developed a four-item measure of resident satisfaction and, using structural equation modeling, found that economic, social, environmental, and institutional dimensions were predictors of residents' satisfaction with tourism, with institutions being the strongest predictor, followed by the economic and social dimensions. Shen and Cottrell (2008) highlighted the importance of considering all four dimensions when monitoring sustainable tourism.

Jackson and Murphy (2006) developed a series of questions aimed at measuring competition and interaction among tourism businesses. Murphy and Cooper (2004) also measured the competitiveness of a destination and tourism investment. Similarly, Zhang, Ruhanen, Murphy, and Cooper (2004) developed a local-level development potential index to assist in investment decision making and help guide government policy making. The index questionnaire was distributed to business leaders, politicians, administrators, and interest groups in five regions in Australia. Broadly, the questionnaire asked respondents about perceived potential and current constraints for future tourism development, future tourism strategic options, knowledge of selected theories, and personal information. In particular, the scale developed a detailed assessment of the constraints to future development, which included economic, administrative, political, transport, and other constraints. Shen and Cottrell (2008) developed three to five survey items to measure the four sustainability dimensions: economy, society, environment, and institutions. However, their five-item institutional index, while providing a broad overview, could not delve in depth into all aspects of tourism business institutions, such as learning, and agility and adaptability.

\section{Measures of Institutions in the Broader Literature}

With a lack of institutional measurement systems in the tourism literature, it was necessary to look more broadly to underpin the indices with theory. There has been growing recognition in economics, ecology, and organizational change literature that change can be influenced by institutions. This saw some researchers link structural change with institutions, resulting in the development of transformation theory (Corpataux \& Crevoisier, 2007; Malaska, 1991). Frameworks to emerge from related economic literature included the structure-conduct-performance paradigm (Ferguson \& Ferguson, 1994) and the Regression Theorem (Boettke, Coyne, \& Leeson, 2008), among others. Similarly, the adaptive capacity literature has recognized the integral role of institutions, governance, and management in the change process (Haddad, 2005). For example, the Adaptive Capacity Wheel is a tool to assess if institutions stimulate the adaptive capacity of a society to respond to climate change (Gupta et al., 2010).

In the organizational literature, business institutions have been assessed through scales and indices. 
The Learning Organizations (LO) framework (Senge, 1990) has previously been proposed as a valuable analytical tool for assessing the learning process in tourism organizations (Prideaux, Laws, \& Faulkner, 2003; Schianetz et al., 2007), as has Spitzer's (2007) Transforming Performance Measurement (TPM) framework (McLennan et al., 2012). However, unlike the LO framework, the TPM framework is yet to be applied in a tourism context, particularly as a collective measurement tool for tourism destinations.

The TPM framework presented a series of scales assessing performance measurement, organizational trust, collaboration, organizational agility, and decision-making processes of businesses. Spitzer (2007) argued that transformational measurement is a way of facilitating organizational learning, emphasizing that transformation is a social process and that while "maturity" can be seen as stagnant, it can also mean the system is more effective and fundamentally "much better" (Spitzer, 2007, p. 177). Spitzer (2007) suggested that organizations can control transformation through performance measurement and monitoring. The TPM framework is a novel and comprehensive way to quantitatively assess transformation in an organization's institutions. By adapting concepts such as the TPM framework, which have evolved in LO literature, tourism institutions at both the individual business level and the political level can be monitored collectively, thereby developing a tool for managing tourism system learning.

From the review of the literature, eight institutional constructs relevant for tourism organizations and destinations were identified. Table 1provides an overview of these constructs and provides justification for their inclusion within the set of indexes developed in this research.

\section{Method}

\section{Developing Indices}

An index is a composite ordinal measures of a construct that can indicate a person's score compared to other people (Colton \& Covert, 2007). That is, a respondent's score on an index is determined by their responses to a series of questions, with each question providing some indication of the construct (or factor) being measured (DeVellis,
2003). Indices summarize and rank order the series of indicators into a single score measuring the latent constructs by accumulating scores assigned to individual indicators (Babbie, 1990). Indices do not need to be unidimensional, which means more than one dimension of a concept can be reflected in an index, thus enabling a measurement of complex multifaceted constructs (Denzin, 2006).

Indices are primarily used to collect causes, symptoms, or outcomes (Colton \& Covert, 2007). Unlike a scale, an index needs only to have convergent (the indicators hang together), content, and face validity (Singh, 2007). While other tools can be used to assess the validity of an index, this is not an essential for its development (Babbie, 1990). For this research the development of indices was considered more appropriate than unidimensional scales, as the goal was to measure an outcome or current state, and the constructs were complex and not always unidimensional. The advantage of an index over a single item is the range of gradiations it offers in the measurement of a variable. Altogether, the index items constitute a more complete and reliable measure of the construct than each individual indicator (Spector, 1992).

The literature debates whether objective or subjective measures are more appropriate for use in the indices (Andereck \& Nyaupane, 2011). Those who support objective measures (e.g., gross regional product, unemployment rates) argue that they are quantifiable aggregate measures (Simmons, Yonk, $\&$ Fawson, 2010). Costanza et al. (2008) argued that the difference between objective and subjective measures is illusionary, because objective measures are proxies for subjective indicators. Indeed, a truly objective set of indicators is elusive as selecting some indicators and not others is a subjective process with selection bias (Simmons et al., 2010). For this research, only subjective measures were considered; however, more objective measures could be incorporated to broaden the institutional assessment beyond the perceptions of managers in further research.

\section{Surveying}

To develop the institutional indices, a survey of business owners or managers and government employees was undertaken in three local govern- 
Table 1

Institutional Constructs to Arise From the Literature

Institutional Construct

Discussion

Source(s) of

Indicators

Competition

Management processes

Performance measurement Flood (1999) noted

Data and research

Collaboration

Benchmarking

Learning

Agility and adaptability (Zahra, 2006). monitoring.
Competitiveness is important for destination development and there are comprehensive frameworks and indicators of competitiveness in the literature (Dwyer \& Kim, 2003; Jackson \& Murphy, 2006).

Management processes influence decision-making and enable or restrict adaptability, benchmarking and the adoption of new practices (Broderick, Garry, \& Beasley, 2010). There is a need to understand management processes to determine how a system will behave, and to develop dynamic, effective and efficient strategies for destination development

ood (1999) noted that organizations can generate their own future (or self-organize). Likewise, Spitzer (2007) discusses how organizations can control transformation processes through performance measurement and

Data and research can aid learning, agility and success of a destination, yet few institutional assessments consider this element (McLennan et al., 2012). Understanding the impact of research on a system is difficult due to the researcher and the object of research not existing independently (Skyttner, 2006).

A lack of collaboration can result in tourism development being difficult and less effective, while clusters can enable development (Sorenson \& Epps, 2003). Tools have previously been developed to measure collaboration and clustering (Jin, Weber, \& Bauer, 2012).

Benchmarking practices can provoke change and best practice (Longbottom, 2000). Service sector organizations are typically less likely to benchmark as they are often small firms with constraints to benchmarking (Broderick et al., 2010).

The organizational change literature suggests that systems learn and that this allows a system to cope with change. Learning occurs by developing institutions to stabilize or direct a system (Argyris \& Schon, 1996) and can ensure sustainable development (Schianetz et al., 2007).

It has been recognized that adaptability and agility are important to the survival of a system and its ability to cope with change (Graetz \& Smith, 2006; Folke et al., 2002).
Jackson and Murphy (2006), Murphy and Cooper (2004)

Spitzer (2007)

Spitzer (2007)

Spitzer (2007)

Jackson and Murphy (2006), Jin et al. (2012)

Spitzer (2007)

Spitzer (2007)

Spitzer (2007) ment areas (LGAs): Murweh Shire, Hervey Bay, and the Gold Coast, all in Queensland, Australia. To select items for the indices, indicator statements of the constructs were identified from the literature and complied into an item pool (sources in Table 1). Once a large number of statements had been collected, the list was double checked for readability, face validity, relevance, and missing indicators. The entire list of statements was too large to be administered at one time; thus it was necessary to refine the list, by omitting repetitive and irrelevant statements, to ensure the survey had the best chance of being completed and answered accurately (DeVellis, 2003; Singh, 2007). The result was eight institutional indices that assessed competition, management processes, performance measurement, data and research capabilities, col- laboration efforts, benchmarking processes, learning ability, and agility and adaptability.

The survey tool was a self-completion questionnaire, conducted either online via SurveyMonkey (a web-based survey tool available at www.survey monkey.com) or in hard copy. The survey asked business and government respondents about their organizations' structure and planning processes and then asked them to complete the institutional indicator assessment of their businesses. All indicator statements were collected on Likert-type scales, which ranked responses from $1=$ "strongly agree" to $5=$ "strongly disagree." Likert-type scales are widely used in social, behavioral, and marketing research (Dawes, 2008). To further ensure validity, the questionnaire underwent expert panel review and pilot testing. Once administered, a sample of 
281 business owners or managers and 85 government employees was achieved in the three local areas from September to December 2009.

\section{Data Preparation, Weighting, and Creating the Indices}

The data were downloaded from SurveyMonkey in Excel format and loaded into STATA v11.0, a data analysis and statistical software package, for analysis. The survey asked several questions to identify tourism organizations. Specifically, business respondents were asked whether their organization sold any goods or services to visitors to the region and if the organization primarily supplied goods or services to visitors to the region (rather than to locals). Government respondents were asked if they worked in a position that related to, or overlapped with, any tourism-related functions, planning, governance, or policies (which was appropriate as in some regional areas tourism policy may be handled by economic development officers or planners). If respondents answered yes to these questions they were deemed a tourism-related respondent, but they could also be identified as being tourism dependent. An alternative method to identify tourism-related organizations is the Tourism Satellite Accounting method; however, when working at a local destination level, this modeling approach may not provide accurate location specific information.

The sample framework was a stratified random sample that classified the population into mutually exclusive groups and sampled within these groups; this helped to reduce sampling error and bias (Cook, Heath, \& Thompson, 2000). The data from the business survey were weighted to the number of Australian businesses by industry division for each of the LGAs to further improve representativeness (Australian Bureau of Statistics, 2007).

To create the indices, the items were standardized, which means that the mean is set to 0 and the variance is set to 1 prior to summing. This practice is employed to prevent variables with larger ranges or prevalence from exerting a greater influence on the index (Australian Bureau of Statistics, 2006). Negative statements were reverse coded to ensure all items in the index had the same sign direction for the creation of a sensible and usable index
(StataCorp, 2009). That is, for the negative statements, 1 was recoded to 5 and 2 was recoded to 4 , and vice versa. Next, the items in each question set were equally weighted and combined using simple averages to create the indices. Generally, the literature suggests the use of equal weighting (unless there are compelling reasons for differential weighting) because this is the most common type of index and is more appropriate for use with statistical measures (DeVellis, 2003).

\section{Assessing Reliability and Validity}

While an index needs only have convergent, content, and face validity (Singh, 2007), other tools can be used to assess the validity of an index (Babbie, 1990). It was considered appropriate to undertake additional reliability and validity tests to gain a greater insight into the indices that were developed and the constructs that were being measured. Thus, following the development of the indices, they were tested in STATA v11.0 for reliability using the Spearman-Brown Prophecy Formula (Nunnally $\&$ Bernstein, 1994). This formula generates a scale reliability alpha that is identical to Cronbach's alpha (Cronbach, 1951) when standardized means are used. As it is identical, this measure will be referred to as Cronbach's alpha in the remainder of this article. Cronbach's alpha is a common method for testing the internal consistency of an index or scale, meaning that it checks that each item in the index is measuring the same or a similar construct (Totten, Panacek, \& Price, 1999). If the alpha value is "high" there is evidence that the items measure an underlying (or latent) construct. Generally, if Cronbach's alpha is equal to or greater than 0.7 the index or scale is considered robust (Langbein \& Felbinger, 2006). However, some researchers suggest that an acceptable precision is if Cronbach's alpha is equal to or greater than 0.6 (Asah, 2008; DeVellis, 2003). Indeed, Costello and Osborne (2005) argue that in the social sciences common precision levels range between 0.4 and 0.7 .

While useful, Cronbach's alpha should be used with caution as its results can be misleading (Shelby, 2011). Although Cronbach's alpha increases as the interitem correlation increases, the alpha value is dependent on the number of items. This is an issue as the literature generally advises that to develop 
robust indices parsimony when determining the number of items is essential. Yet Cronbach's alpha is weighted so that more items result in a higher alpha score, thereby giving the appearance that indices with more items are superior (UCLA Academic Technology Services, 2011).

Factor analysis, another method for evaluating the relationship between the items in an index and the construct (DeVellis, 2003), was used to assess the dimensionality of the indices. While indices need not be unidimensional, it was considered important to assess the dimensionality of the data to provide a better understanding of the construct being measured (Singh, 2007). Principal Component Factor (PCF) analysis is a data reduction technique that assesses and summarizes all variance in the data (Grimm \& Yarnold, 1995). Generally, items with a strong correlation to others in the battery are given high weights. Using PCF analysis, eigenvalues were calculated to provide a way of estimating the degree to which a particular factor is represented in the index by assessing variance (Australian Bureau of Statistics, 2006). From this, STATA automatically calculates the number of factors that are retained, thereby providing an indication of the dimensionality of the index. PCF analysis also provides an indication of uniqueness of each variable in the battery, which indicates how much of the variable is explained by the retained factors.
This can help to determine which variables may not have a good fit within the index (StataCorp, 2009).

PCF analysis is based on Pearson correlations, which assess linear relationships and therefore can be influenced by differences in latent variable distributions. Despite this, researchers have found PCF to be reliable, even when the latent variables are not normally distributed (Dudzinski, Norris, Chmura, \& Edwards, 1975). Thus, to retain objectivity and aid the interpretation process the variables were not transformed to adjust for skewed distributions. Ultimately, an index is tested through external validation and its usefulness for explaining the construct accurately in later analyses (Babbie, 1990).

\section{Results}

\section{The Competition Index Results}

Table 2 presents the Competition Index variables, associated questions, interitem correlations (covariance), and Cronbach's alpha results. The index received an overall scale reliability coefficient (Cronbach's alpha) of 0.52. Two of the variables (Compet3 and Compet5) entered the scale as negatively correlated and thus their signs were reversed. The likelihood ratio (LR) test of the independence of the PCF model was significant (Prob $>$ $\left.\chi^{2}=<0.001\right)$, indicating that the results are meaningful. Table 2 also reveals that four factors were

Table 2

Competition Index

\begin{tabular}{|c|c|c|c|c|c|c|c|}
\hline Item & Item Label & Alpha & $\begin{array}{c}\text { Factor } \\
1\end{array}$ & $\begin{array}{l}\text { Factor } \\
2\end{array}$ & $\begin{array}{l}\text { Factor } \\
3\end{array}$ & $\begin{array}{l}\text { Factor } \\
\quad 4\end{array}$ & Uniqueness \\
\hline Compet1 & Local businesses in your industry are generally innovative & 0.466 & 0.623 & 0.055 & -0.302 & 0.237 & 0.462 \\
\hline Compet2 & $\begin{array}{l}\text { Local businesses in your industry are generally successful } \\
\text { (rarely fail) }\end{array}$ & 0.438 & 0.671 & -0.143 & -0.322 & 0.123 & 0.411 \\
\hline Compet3 $^{\mathrm{a}}$ & $\begin{array}{l}\text { It is difficult to start up a new business in your industry in } \\
\text { this region }\end{array}$ & 0.505 & -0.289 & 0.502 & 0.458 & 0.144 & 0.434 \\
\hline Compet4 & $\begin{array}{l}\text { Your industry is a well-established and mature sector in } \\
\text { this region }\end{array}$ & 0.472 & 0.651 & 0.356 & 0.006 & -0.185 & 0.416 \\
\hline Compet5 ${ }^{\mathrm{a}}$ & $\begin{array}{l}\text { There is not enough demand to increase the number of } \\
\text { businesses in your industry in this region }\end{array}$ & 0.527 & -0.080 & 0.784 & -0.006 & -0.059 & 0.375 \\
\hline Compet6 & $\begin{array}{l}\text { More local businesses would enhance your industry's } \\
\text { competitiveness and appeal in this region }\end{array}$ & 0 & 0.271 & -0 . & 0.480 & 0.004 & 9 \\
\hline Compet7 & Your local industry is competitive against other regions & 0.504 & 0.357 & -0.072 & 0.434 & -0.679 & 0.217 \\
\hline Compet8 & Your industry is well integrated into this region & 0.487 & 0.586 & 0.387 & 0.164 & -0.023 & 0.480 \\
\hline $\begin{array}{l}\text { Compet9 } \\
\text { Test scale }\end{array}$ & $\begin{array}{l}\text { Organizations in your industry directly compete with } \\
\text { other similar local operators }\end{array}$ & $\begin{array}{l}0.520 \\
0.520\end{array}$ & 0.283 & 0.011 & 0.534 & 0.642 & 0.223 \\
\hline
\end{tabular}

Method: Principal Component Factors (unrotated); retained factors $=4$; number of parameters $=30$; sample $=366$.

aNegative statement: reverse coded for index development. 
Table 3

Management Processes Index

Item

Item Label

Alpha $\begin{array}{ccc} & 1 & 2\end{array}$ Uniqueness

Manage1 Your organization is continually aligning/realigning its performance to a regional industry strategy

Manage $2^{\mathrm{a}}$ There is clear leadership in this region for your industry

Manage3 Your organization works with government agencies to develop and revise industry strategies

Manage4 It is important to measure your organization's performance

Manage $^{\text {a }}$ Measuring the performance of your organization and making improvements is essential for remaining competitive

Manage $^{\mathrm{a}}$ All the important factors for the present and future success of your organization are being effectively measured

Manage $7^{\text {a }}$ Your organization is currently performing well

Manage8 You put aside time to undertake performance measurement and research

Test scale

$\begin{array}{rrrr}0.724 & 0.622 & 0.464 & 0.398 \\ 0.746 & 0.478 & 0.687 & 0.300 \\ & & & \\ 0.758 & 0.410 & 0.694 & 0.351 \\ 0.731 & 0.675 & -0.445 & 0.347 \\ & & & \\ 0.722 & 0.708 & -0.353 & 0.375 \\ & & & \\ 0.718 & 0.713 & -0.130 & 0.475 \\ 0.745 & 0.551 & -0.240 & 0.639 \\ 0.720 & 0.684 & -0.185 & 0.498 \\ 0.759 & & & \end{array}$

Method: Principal Component Factors (unrotated), retained factors $=2$, number of parameters $=15$; sample $=366$.

${ }^{a}$ Sample $=281$ for this item as only business respondents were applicable.

retained, with factor 1 accounting for $22 \%$ of the variance in the index, followed by factor $2(17 \%)$, factor $3(13 \%)$, and factor $4(11 \%)$. The high number of factors may reflect the relatively low Cronbach's alpha achieved by this index. Table 2 displays the factor loadings and the uniqueness of the variables, with the uniqueness of the variables in the index being reasonably low. Rotating the factor loadings indicates that Compet1, Compet2, and Compet4 load into factor 1, with Compet5 and Compet6 loading into factor 2, Compet7 loading

into factor 3, and Compet9 loading into factor 4. Compet 3 and Compet 8 did not load above 0.5 into any of the four factors. This suggests that competition is a highly complex subject that can be thought about in a variety of ways, which supports arguments by Hong (2009).

\section{The Management Processes Index Results}

Table 3 presents the Management Processes Index variables and the associated questions as well

Table 4

Performance Measurement Processes Index

Item

Item Label

Factor

\begin{tabular}{lllll}
\hline Perform1 & $\begin{array}{l}\text { Your organization's current performance measurement and decision-making tools } \\
\text { can effectively guide high-quality decision making } \\
\text { You have a variety of tools for measuring the performance of your business and } \\
\text { understand how to interpret them }\end{array}$ & 0.902 & 0.787 & 0.381 \\
Perform2 & $\begin{array}{l}\text { Your organization's performance measurement system is continually improved and } \\
\text { updated }\end{array}$ & 0.903 & 0.788 & 0.379 \\
Perform3 & $\begin{array}{l}\text { Your organization is open to adopting new and innovative performance measurement } \\
\text { tools if they are appropriate }\end{array}$ & 0.899 & 0.828 & 0.314 \\
Perform4 & $\begin{array}{l}\text { A number of different performance measurement tools are used to monitor this } \\
\text { organization }\end{array}$ & 0.781 & 0.390 \\
Perform5 & $\begin{array}{l}\text { Performance measurement tools are regularly reviewed, revised or eliminated as } \\
\text { appropriate }\end{array}$ & 0.903 & 0.784 & 0.386 \\
Perform6 & $\begin{array}{l}\text { The performance measurement tools are appropriate and of the right number (not too } \\
\text { many, not too few) }\end{array}$ & 0.922 & 0.325 \\
Perform7 & $\begin{array}{l}\text { Old measures are reduced when new and more appropriate performance measures are } \\
\text { added }\end{array}$ & 0.740 & 0.902 \\
Perform8 & 0.902 & 0.790 & 0.376 \\
Perform9 & $\begin{array}{l}\text { Performance measurement is becoming more automated } \\
\text { Test scale }\end{array}$ & 0.913 & \\
\hline
\end{tabular}

Method: Principal Component Factors (unrotated); retained factors $=1$; number of parameters $=9$; sample $=366$. 
as the interitem correlations (covariance) and Cronbach's alpha results. The index received an overall reliability coefficient (Cronbach's alpha) of 0.76. The LR test of the independence of the PCF model was significant (Prob $>\chi^{2}=<0.001$ ), indicating that the results are meaningful. Table 3 indicates that two factors were retained, with factor 1 accounting for $38 \%$ of the variance in the index and factor 2 accounting for $20 \%$. Table 3 displays the factor loadings and the uniqueness of the variables. The uniqueness of most of the variables in the index was reasonably low. However, Manage 7 was found to be $64 \%$ unique, implying that the two retained factors do not explain the variation in the variable very well. Yet Manage7 scored reasonably well with a similar Cronbach's alpha to the other variables in the set. This suggests that this variable can contribute to the index and help measure management processes, but that it also measures another factor that the rest of the index does not, namely business performance.

\section{The Performance Measurement Processes Index Results}

Table 4 presents the Performance Measurement Processes Index variables and the associated questions as well as the interitem correlations (covariance) and Cronbach's alpha results. The index achieved an overall reliability coefficient (Cronbach's alpha) of 0.91. The LR test of the independence of the PCF model was significant (Prob $\left.>\chi^{2}=0.001\right)$, indicating that the results are meaningful. Table 4 indicates that only one factor was retained, with factor 1 accounting for $59 \%$ of the variance in the index. Table 4 displays the factor loadings and the uniqueness of the variables, with the uniqueness of most of the variables in the index being relatively low. However, Perform9 was found to be $65 \%$ unique, indicating that the retained factor does not explain the variation in the variable very well. However, Perform9 scored the highest Cronbach's alpha score and this was similar to the alpha scores of the other variables in the set. This suggests that this variable can contribute to the index and help measure performance measurement processes, but it also measures another factor that the rest of the index does not.

\section{The Data and Research Capabilities Index Results}

Table 5 presents the Data and Research Capabilities Index variables and the associated questions, as well as the index interitem correlations (covariance) and Cronbach's alpha results. The index received an overall reliability coefficient (Cronbach's alpha) of 0.88 . The LR test of the independence of the PCF model was significant (Prob $>\chi^{2}=<0.001$ ), indicating that the results are meaningful. Table 5 indicates that two factors were retained, with factor 1 accounting for $41 \%$ and factor 2 accounting for $22 \%$ of the variance in the index. Table 5 displays the factor loadings and the uniqueness of the variables. The uniqueness values of most of the variables in the index were reasonably low. However, Research7 was found to be $67 \%$ unique, implying that the retained factors do not explain the variation in the variable very well. Despite this, Research7 scored well on the Cronbach's alpha score and this was similar to the alpha scores of the other variables in the set. This suggests that this variable can contribute to the index and help measure data and research capabilities, but that it also measures another factor that the rest of the index does not.

\section{The Collaboration Efforts Index Results}

Table 6 presents the Collaboration Efforts Index variables and the associated questions, as well as the interitem correlations (covariance) and Cronbach's alpha results. The Collaboration Efforts Index achieved an overall reliability coefficient (Cronbach's alpha) of 0.86 . The LR test of the independence of the PCF model was significant (Prob $>\chi^{2}=<0.001$ ), indicating that the results are meaningful. Table 6 indicates that five factors were retained, with factor 1 accounting for $35 \%$ of the variance in the index, followed by factor 2 accounting for $10 \%$, factor 3 accounting for $9 \%$, factor 4 accounting for $7 \%$, and factor 5 accounting for $6 \%$. Table 6 displays the factor loadings and the uniqueness of the variables. The uniqueness values of most of the variables in the index were reasonably low. However, Collab15 was found to be $66 \%$ unique, implying that the retained factors do not explain the variation in the variable very well. However, Collab15 scored well on the Cronbach's alpha score 
Table 5

Data and Research Capabilities Index

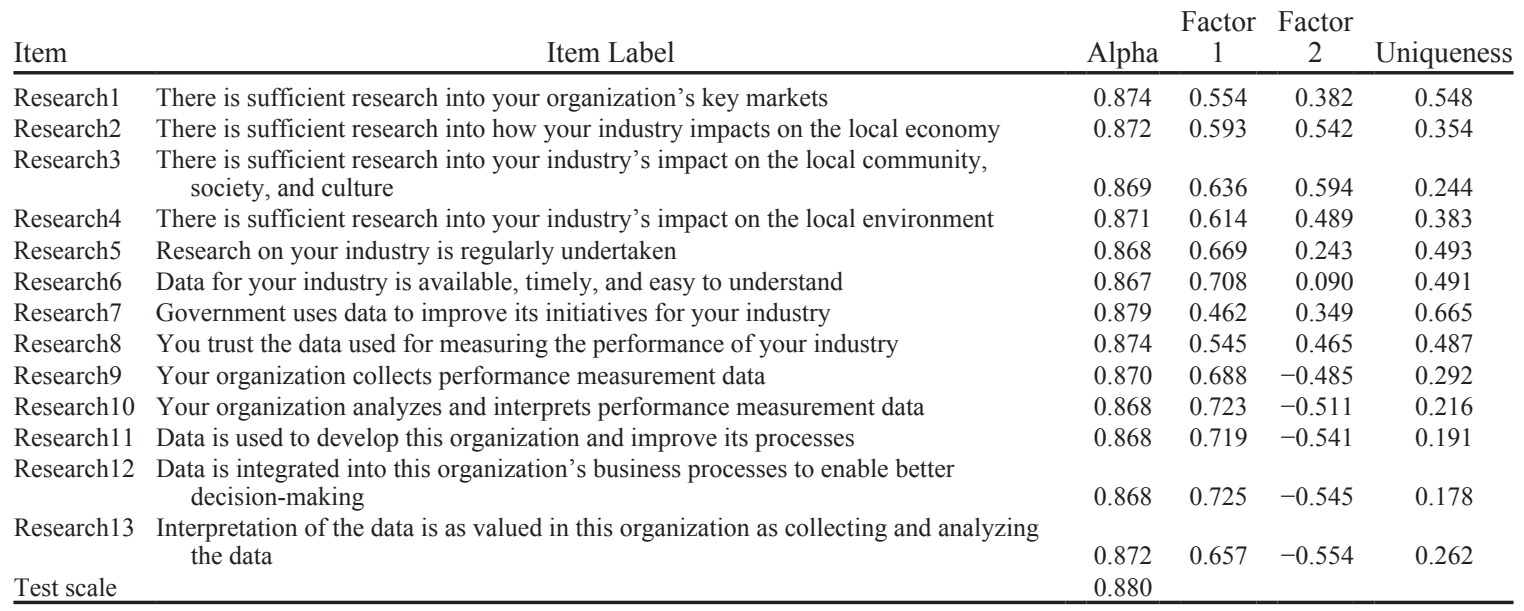

Method: Principal Component Factors (unrotated); retained factors $=2$; number of parameters $=25$; sample $=366$.

Table 6

Collaboration Efforts Index

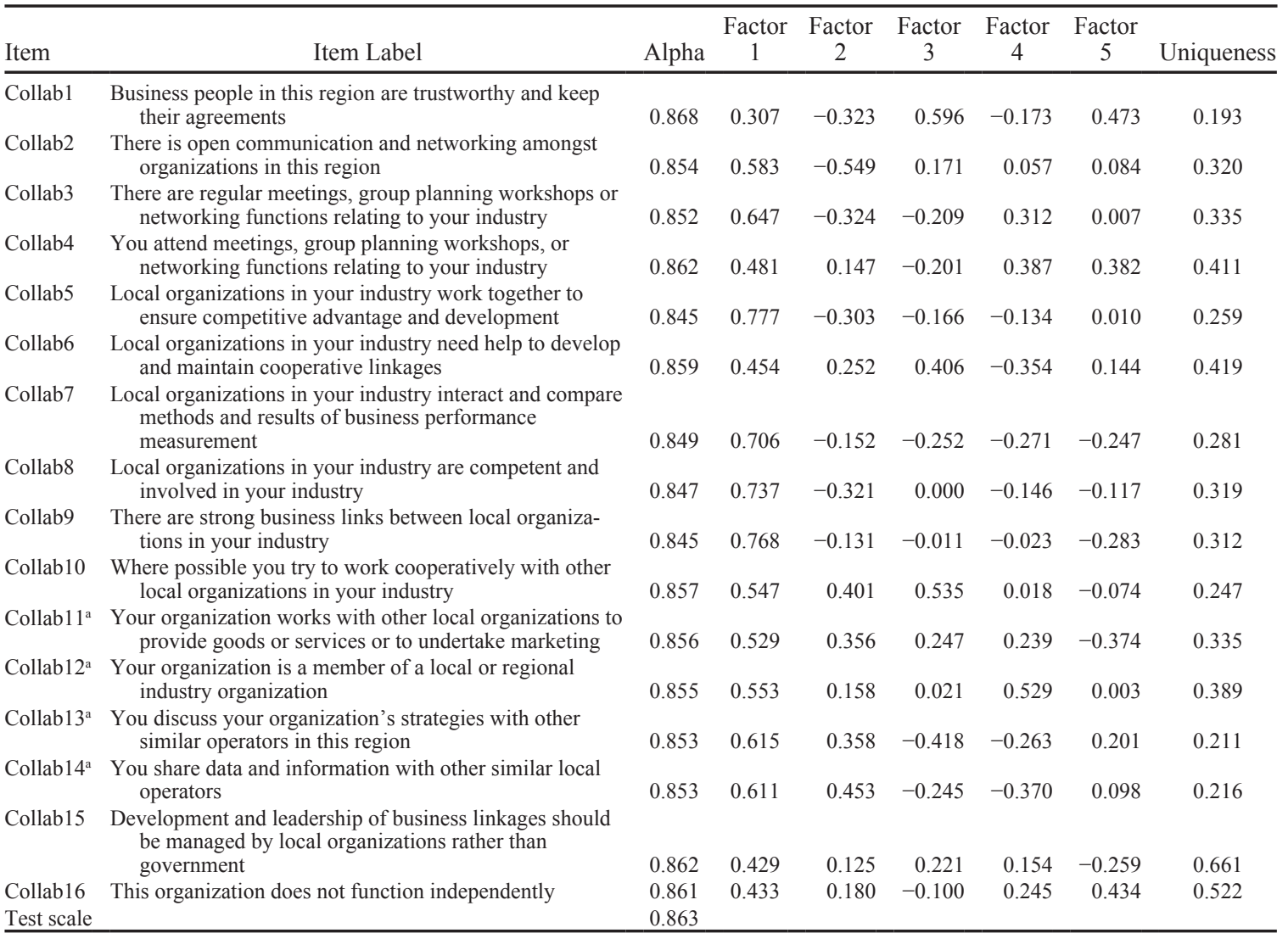

Method: Principal Component Factors (unrotated), retained factors $=5$, number of parameters $=70$; sample $=366$.

${ }^{a}$ Sample $=281$ for this item as only business respondents were applicable. 
and this was similar to the alpha scores of the other variables in the set. This suggests that this variable can contribute to the index and help measure collaboration efforts, but that it also measures another factor that the rest of the index may not.

\section{The Benchmarking Processes Index Results}

Table 7 presents the Benchmarking Processes Index variables and the associated questions, as well as the interitem correlations (covariance) and Cronbach's alpha results. The Benchmarking Processes Index received an overall reliability coefficient (Cronbach's alpha) of 0.81 . The LR test of the independence of the PCF model was significant (Prob $>\chi^{2}=<0.001$ ), indicating that the results are meaningful. Table 7 indicates that one factor was retained, with factor 1 accounting for $57 \%$ of the variance in the index. Table 7 displays the factor loadings and the uniqueness of the variables. The uniqueness values of most of the variables in the index were generally low.

\section{The Learning Ability Index Results}

Table 8 presents the Learning Ability Index variables and the associated questions, as well as the interitem correlations (covariance) and Cronbach's alpha results. The index received an overall reliability coefficient (Cronbach's alpha) of 0.83 . The LR test of the independence of the PCF model was significant (Prob $>\chi^{2}=<0.001$ ), indicating that the results are meaningful. Table 8 indicates that two factors were retained, with factor 1 accounting for $43 \%$ of the variance in the index, and factor 2 accounting for $11 \%$. Table 8 displays the factor loadings and the uniqueness of the variables. The uniqueness values of most of the variables in the index were reasonably low. However, Learn 2 was found to be $63 \%$ unique, implying that the retained factors do not explain the variation in the variable very well. However, Learn 2 scored well on the Cronbach's alpha score and this was similar to the alpha scores of the other variables in the set. This indicates that the variable contributes to the index, but that it also measures another factor that the rest of the index does not.

\section{The Agility and Adaptability Index Results}

Table 9 presents the Agility and Adaptability Index variables, the associated questions, the interitem correlations (covariance), and Cronbach's alpha results. The index received an overall reliability coefficient (Cronbach's alpha) of 0.95 . The LR test of the independence of the PCF model was significant (Prob $>\chi^{2}=<0.001$ ), indicating that the results are meaningful. Table 9 indicates that three factors were retained, with factor 1 accounting for $50 \%$ of the variance in the index, and factor 2 and factor 3 accounting for $7 \%$ and $5 \%$, respectively. Table 9 displays the factor loadings and the uniqueness of the variables. The uniqueness values of the variables in the index were all low. This suggests

Table 7

Benchmarking Processes Index

\begin{tabular}{|c|c|c|c|c|}
\hline Item & Item Label & Alpha & $\begin{array}{c}\text { Factor } \\
1\end{array}$ & Uniqueness \\
\hline Bench1 & This organization benchmarks against similar organizations & 0.770 & 0.750 & 0.437 \\
\hline Bench2 & Benchmarking measures are developed and used & 0.742 & 0.818 & 0.332 \\
\hline Bench3 & $\begin{array}{l}\text { It is necessary to assess and benchmark how this organization is performing on an } \\
\text { ongoing basis }\end{array}$ & 0.738 & 0.827 & 0.317 \\
\hline Bench4 & $\begin{array}{l}\text { There is benchmarking which compares the performance of this region to other } \\
\text { regions }\end{array}$ & 0.801 & 0.646 & 0.583 \\
\hline Bench5 & $\begin{array}{l}\text { It is necessary to assess and benchmark how your local industry is performing on an } \\
\text { ongoing basis }\end{array}$ & 0.783 & 0.704 & 0.504 \\
\hline Test scale & & 0.805 & & \\
\hline
\end{tabular}

Method: Principal Component Factors (unrotated); retained factors $=1$; number of parameters $=5$; sample $=366$. 
Table 8

Learning Ability Index

\begin{tabular}{|c|c|c|c|c|c|}
\hline Item & Item Label & Alpha & $\begin{array}{c}\text { Factor } \\
1\end{array}$ & $\begin{array}{l}\text { Factor } \\
2\end{array}$ & Uniqueness \\
\hline Learn1 & $\begin{array}{l}\text { Progress is being made to measure intangible sources of value (e.g., talent, } \\
\text { knowledge and innovation) }\end{array}$ & 0.826 & 0.527 & 0.541 & 0.430 \\
\hline Learn2 & Your organization learns from entities from other regions & 0.824 & 0.545 & 0.264 & 0.634 \\
\hline Learn3 & Technology is being used to support/enhance performance measurement & 0.819 & 0.595 & 0.392 & 0.493 \\
\hline Learn4 & In this region, your industry is adaptable and able to adjust to changes & 0.809 & 0.691 & -0.271 & 0.449 \\
\hline Learn5 & $\begin{array}{l}\text { Measurement is used as frequently for improvement and learning as it is for } \\
\text { monitoring, reporting and rewarding }\end{array}$ & 0.807 & 0.707 & -0.275 & 0.425 \\
\hline Learn6 & Your organization learns from other local organizations & 0.806 & 0.719 & -0.344 & 0.365 \\
\hline Learn7 & Your organization places a priority on research/development & 0.805 & 0.710 & 0.232 & 0.443 \\
\hline Learn8 & $\begin{array}{l}\text { Your organization undertakes experiments or pilot tests when starting a new } \\
\text { project/product/market }\end{array}$ & 0.816 & 0.630 & 0.136 & 0.585 \\
\hline Learn9 & $\begin{array}{l}\text { You and your staff have local access to training courses offered beyond high } \\
\text { school level qualifications }\end{array}$ & $\begin{array}{l}0.805 \\
0.830\end{array}$ & 0.730 & -0.388 & 0.316 \\
\hline
\end{tabular}

Method: Principal Component Factors (unrotated); retained factors $=2$; number of parameters $=17$; Sample $=366$.

Table 9

Agility and Adaptability Index

\begin{tabular}{|c|c|c|c|c|c|c|}
\hline Item & Item Label & Alpha & $\begin{array}{c}\text { Factor } \\
1\end{array}$ & $\begin{array}{c}\text { Factor } \\
2\end{array}$ & $\begin{array}{c}\text { Factor } \\
3\end{array}$ & Uniqueness \\
\hline Adapt1 & Can implement changes in its business processes quickly & 0.946 & 0.759 & -0.293 & -0.144 & 0.317 \\
\hline Adapt2 & Can incorporate new technology quickly & 0.946 & 0.745 & -0.256 & -0.105 & 0.369 \\
\hline Adapt3 & Can implement small changes quickly & 0.946 & 0.779 & 0.077 & -0.215 & 0.342 \\
\hline Adapt4 & Can implement large scale changes quickly & 0.947 & 0.695 & -0.472 & 0.153 & 0.270 \\
\hline Adapt5 & Can adapt to change easily & 0.945 & 0.806 & -0.320 & 0.035 & 0.247 \\
\hline Adapt6 & Can respond quickly to new opportunities or threats & 0.946 & 0.771 & -0.164 & -0.188 & 0.343 \\
\hline Adapt7 & Can solve problems quickly and effectively & 0.946 & 0.780 & -0.068 & -0.313 & 0.289 \\
\hline Adapt8 & Can make and implement decisions quickly & 0.945 & 0.812 & -0.078 & -0.334 & 0.223 \\
\hline Adapt9 & Has considerable error tolerance (possible to make mistakes) & 0.951 & 0.423 & -0.336 & 0.418 & 0.533 \\
\hline Adapt10 & Has flexible labor (can redeploy/retrain employees quickly) & 0.949 & 0.543 & -0.291 & 0.162 & 0.594 \\
\hline Adapt11 & Has good communication & 0.946 & 0.763 & 0.020 & -0.061 & 0.414 \\
\hline Adapt12 & Is flexible compared to its competitors & 0.947 & 0.681 & 0.009 & 0.136 & 0.518 \\
\hline Adapt13 & Is designed to enable change & 0.945 & 0.811 & -0.100 & 0.150 & 0.310 \\
\hline Adapt14 & Is designed to be simple, lean and flexible & 0.946 & 0.722 & -0.017 & 0.015 & 0.478 \\
\hline Adapt 15 & Values learning from experience & 0.946 & 0.762 & 0.301 & -0.158 & 0.304 \\
\hline Adapt16 & Values collaboration (between staff and other organizations) & 0.947 & 0.688 & 0.365 & 0.162 & 0.368 \\
\hline Adapt17 & Values guidelines more than rules & 0.947 & 0.656 & 0.228 & 0.116 & 0.504 \\
\hline Adapt18 & Values cross-training & 0.947 & 0.687 & 0.270 & 0.268 & 0.383 \\
\hline Adapt19 & Values outsourcing non-core capabilities & 0.949 & 0.533 & 0.217 & 0.514 & 0.405 \\
\hline Adapt20 & Values employees that can deal with various $\mathrm{s}$ & 0.947 & 0.672 & 0.490 & -0.178 & 0.277 \\
\hline Adapt21 & Values employees who try new ways of doing things & 0.947 & 0.681 & 0.430 & 0.048 & 0.349 \\
\hline Test scale & & 0.949 & & & & \\
\hline
\end{tabular}

Method: Principal Component Factors (unrotated); retained factors $=3$; number of parameters $=60$; sample $=366$.

that the variables are generally explained by the three retained factors.

\section{Discussion and Conclusion}

Institutions can either deliver or hinder structural development, and so it is essential that they are incorporated in structural change models. Despite the established body of work on scales and indices in tourism and associated fields, the use of institutional indices to assess tourism destinations are underdeveloped. Therefore, the institutional assessment primarily drew on existing scales and indices from both tourism and the broader literature (Table 
1), resulting in eight institutional indices being developed. These indices aimed to assess competitiveness, management processes, performance measurement, data and research capabilities, collaboration efforts, benchmarking processes, learning ability, and agility and adaptability. With the development of tourism institutional indices for the assessment of tourism destinations remaining largely unexplored and theoretically underdeveloped in tourism literature, the development of the institutional indices is a novel contribution to tourism destination literature and does not appear to have been previously developed to this extent within this context.

This research has delivered a series of indicators by which tourism managers can form baseline measures for benchmarking the current institutions within an organization, industry, or destination. This standardized method of institutionally rating organizations to provide an indication of the performance of the industry or destination can enable the ongoing monitoring of institutions across time, as well as allow comparisons with other organizations, industries or destinations. The indices can reveal particular institutions on which organizations or destinations are underperforming; for example, it may be found that an organization is underperforming in its agility and adaptability scale and therefore can implement organizational changes strategies to address this issue. Moreover, the indices also provide a tool to identify sectors of the tourism industry requiring institutional change; for example, small businesses may be identified as having lower institutional performance (i.e., they rank lower on the indices overall) than larger organizations.

Furthermore, at an international, national, or state level, these indices can be used to pinpoint specific destinations, regions, or countries that require institutional development and can highlight which particular areas to focus on, such as learning or research and so on. These indicators are additionally useful as they are a standardized system that can be used to assess the institutions of other industries and across regions, thereby providing a system for comparison and benchmarking. Such comparisons will enable more directed and efficient institutional change to aid the transformational process. Having an in-depth understanding of business institutions will enable businesses and the tourism industry to cope with and direct transformational change.

The institutional indices focused on eight areas: competition, management processes, performance measurement, data and research capabilities, collaboration efforts, benchmarking processes, learning ability, and agility and adaptability. Previous tourism research has focused on competition, competitive behavior and interaction (Jackson \& Murphy, 2006). Expanding the assessment of institutions to include other elements, this current research therefore contributes innovative indices to tourism literature, specifically for assessing the eight identified foci.

Future research should seek to develop the Competition Index by seeking additional and appropriate items that could enhance the index to ensure it is more predictive. The majority of the indices developed in this research were multidimensional, suggesting they are complex and multifaceted concepts. For these indices to be used as scales, they need to be split by the factors, thus further analysis and development of the indices could result in a number of scales to measure the overarching concepts. Development of the indices into scales would allow for assessment of particular influential factors that may underlie the constructs. While this was not a focus of this research it would be of benefit to pursue this avenue in future research.

A fundamental notion behind transformation theory is that there is a need for ongoing change, learning, and adaptability. Therefore, the proposed scales should be continually evaluated and revised to better measure and adapt to changes in the tourism industry. While the developed indices appear to be robust and successfully measure the constructs of interest, a true test of a scale is to determine whether the results portray reality. Thus, the indices should be implemented and analyzed in future research to fully determine their applicability for measuring institutions.

\section{References}

Agarwal, S. (2002). Restructuring seaside tourism: The resort lifecycle. Annals of Tourism Research, 29(1), 2555.

Alipour, H., \& Kilic, H. (2004). Tourism development and planning in constrained circumstances: An institutional appraisal of the Turkish Republic of North Cyprus (TRNC). In D. Hall (Ed.), Tourism and transition: 
Governance, transformation and development (pp. 133146). Wallingford, UK: CABI.

Andereck, K., \& Nyaupane, G. P. (2011). Exploring the nature of tourism and quality of life perceptions among residents. Journal of Travel Research, 50(3), 248-260.

Argyris, C., \& Schon, D. (1996). Organizational learning II: Theory, method, and practice. Reading, MA: Addison-Wesley.

Asah, S. T. (2008). Empirical social-ecological system analysis: From theoretical framework to latent variable structural equation model. Environmental Management, 42(2008), 1077-1090.

Australian Bureau of Statistics. (2006). Socio-economic indexes for areas (SEIFA)- Technical Paper-2006. Retrieved 15th May, 2011, from http://www.abs.gov.au/ ausstats/abs@.nsf/mf/2039.0.55.001/

Australian Bureau of Statistics. (2007). Businesses by industry division by statistical local area by employment size ranges. In Counts of Australian businesses, including entries and exits, Jun 2003 to Jun 2007 (Cat. 8165). Canberra: Author.

Babbie, E. (1990). Survey research methods (2nd ed.). Belmont, CA: Wadsworth Cengage Learning.

Boettke, P. J., Coyne, C. J., \& Leeson, P. T. (2008). Institutional stickiness and the new development economics. American Journal of Economics and Sociology, 67(2), 331-358.

Briedenhann, J., \& Butts, S. (2004). Tourism administration and regional integration under transition: Policy and practice in South Africa. In D. Hall (Ed.), Tourism and transition: Governance, transformation and development (pp. 201-216). Wallingford, UK: CABI.

Broderick, A., Garry, T., \& Beasley, M. (2010). The need for adaptive processes of benchmarking in small business-to-business services. Journal of Business \& Industrial Marketing, 25(5), 324-337.

Colton, D., \& Covert, R. W. (2007). Designing and constructing instruments for social research and evaluation. San Francisco, CA: John Wiley \& Sons.

Cook, C., Heath, F., \& Thompson, R. L. (2000). A metaanalysis of response rates in web- or internet-based surveys. Educational and Psychological Measurement, 60(6), 821-836.

Corpataux, J., \& Crevoisier, O. (2007). Economic theories and spatial transformations clarifying the space-time premises and outcomes of economic theories. Journal of Economic Geography, 7, 285-309.

Costanza, R., Fisher, B., Ali, S., Beer, C., Bond, L., Boumans, R., et al. (2008). An integrative approach to quality of life measurement, research, and policy. Surveys and Perspectives Integrating Environment and Society, 1, 11-15.

Costello, A. B., \& Osborne, J. W. (2005). Best practices in exploratory factor analysis: Four recommendations for getting the most from your analysis. Practical Assessment, Research \& Evaluation, 10(7), 1-9.

Cottrell, S. P., Vaske, J. J., Shen, F., \& Ritter, P. (2007). Resident perceptions of sustainable tourism in
Chongdugou, China. Journal of Society and Natural Resources, 20(6), 511-525.

Cronbach, L. J. (1951). Coefficient alpha and the internal structure of tests. Psychometrika, 16, 297-334.

Dawes, J. (2008). Do data characteristics change according to the number of scale points used? International Journal of Market Research, 50(1), 61-77.

Denzin, N. (2006). Sociological methods: A sourcebook (5th ed.). Piscataway, NJ: Aldine Transaction.

DeVellis, R. F. (2003). Scale development: Theory and applications. Menlo Park, CA: Sage.

Dudzinski, M. L., Norris, J. M., Chmura, J. T., \& Edwards, C. B. H. (1975). Repeatability of principal components in samples: Normal and non-normal data sets. Multivariate Behavioural Research, 10(1), 109-117.

Dwyer, L., \& Kim, C. (2003). Destination competitiveness: Determinants and indicators. Current Issues in Tourism, 6(5), 369-414.

Dwyer, L., Edwards, D., Mistilis, N., Roman, C., Scott, N., \& Cooper, C. (2008). Megatrends underpinning tourism to 2020: Analysis of key drivers for change. Gold Coast: Sustainable Tourism Cooperative Research Centre.

Farrell, B.H., \& Twining-Ward,L. (2004). Reconceptualizing tourism. Annals of Tourism Research, 31(2), 274-295.

Ferguson, P. R., \& Ferguson, G. J. (1994). The structureconduct-performance paradigm. In P. R. Ferguson \& G. J. Ferguson (Eds.), Industrial economics: issues and perspectives (2nd ed., pp. 13-37). New York: New York University Press.

Flood, R. L. (1999). Rethinking the fifth discipline: Learning within the unknowable. London: Routledge.

Folke, C., Carpenter, S. R., Elmqvist, T., Gunderson, L. H., Holling, C. S., \& Walker, B. (2002). Resilience and sustainable development: Building adaptive capacity in a world of transformations. AMBIO: A Journal of the Human Environment, 437-440.

Graetz, F., \& Smith, A. (2006). Critical perspectives on the evolution of new forms of organising. International Journal of Strategic Change Management, 1(1/2), 127142.

Grimm, L. G., \& Yarnold, P. R. (1995). Reading and understanding multivariate statistics. Washington, DC: American Psychological Association.

Gupta, J., Termeer, C., Klostermann, J., Meijerink, S., van den Brink, M., Jong, P., et al. (2010). The adaptive capacity wheel: A method to assess the inherent characteristics of institutions to enable the adaptive capacity of society. Environmental Science \& Policy, 13, 459-471.

Haddad, B. M. (2005). Ranking the adaptive capacity of nations to climate change when socio-political goals are explicit. Global Environmental Change, 15, 165-176.

Hall, D. (2004). Tourism and transition: Governance, transformation and development. Wallingford, UK: CABI.

Hallegatte, S., Ghil, M., Dumas, P., \& Hourcade, J.-C. (2008). Business cycles, bifurcations and chaos in a neoclassical model with investment dynamics. Journal of Economic Behaviour \& Organisation, 67(1), 57-77.

Hong, W. (2009). Global competitiveness measurement for 
the tourism sector. Current Issues in Tourism, 12(2), $105-132$.

Jackson, J., \& Murphy, P. (2006). Clusters in regional tourism: An Australian case. Annals of Tourism Research, 33(4), 1018-1035.

Jin, X., Weber, K., \& Bauer, T. (2012). Impact of clusters on exhibition destination attractiveness: Evidence from Mainland China. Tourism Management, 33(6), 14291439.

Kotlinski, W. (2004). The government's role in stimulating national tourism development: The case of Poland. In D. Hall (Ed.), Tourism and transition: Governance, transformation and development (pp. 65-72). Wallingford, UK: CABI.

Langbein, L. I., \& Felbinger, C. L. (2006). Chapter 8: Designing useful surveys for evaluation. In Public program evaluation: A statistical guide (pp. 192-217). Armonk, NY: M. E. Sharpe.

Longbottom, D. (2000). Benchmarking in the UK: An empirical study of practitioners and academics. Benchmarking: An International Journal, 7(2), 98-117.

Malaska, P. (1991). Economic and social evolution: The transformational dynamics approach. In E. Lazlo (Ed.), The new evolutionary paradigm (pp. 131-156). New York: Gordon and Breach Science Publishers.

Mantzavinos, C., North, D. C., \& Shariq, S. (2004). Learning, institutions, and economic performance. Perspectives on Politics, 2(1), 75-84.

McLennan, C., Ruhanen, L., Ritchie, B., \& Pham, T. (2012). Dynamics of destination development: Investigating the application of transformation theory. Journal of Hospitality and Tourism Research, 36(2), 164-190.

Murphy, P., \& Cooper, C. (2004). Communities as regional destinations. Gold Coast: Sustainable Tourism Cooperative Research Centre.

Mwangi, E. (2006). The footprints of history: Path dependence in the transformation of property rights in Kenya's Maasailand. Journal of Institutional Economics, 2(2), 157-180.

Nunnally, J. C., \& Bernstein, I. H. (1994). Psychometric theory (3rd ed.). New York: McGraw-Hill.

Pavlovich, K. (2003). The evolution and transformation of a tourism destination network: The Waitomo caves, New Zealand. Tourism Management, 24, 203-216.

Prideaux, B., Laws, E., \& Faulkner, B. (2003). Events in Indonesia: Exploring the limits to formal tourism trends forecasting methods in complex crisis situations. Tourism Management, 24(4), 475-487.

Saarinen, J. (2004). 'Destinations in change': The transformation process of tourist destinations. Tourist Studies, $4(2), 161-179$.

Saarinen, J., \& Kask, T. (2008). Transforming tourism spaces in changing socio-political contexts: The case of Parnu, Estonia, as a tourist destination. Tourism Geographies, 10(4), 452-473.

Schianetz, K., Kavanagh, L., \& Lockington, D. (2007). The learning tourism destination: The potential of a learning organisation approach for improving the sustainability of tourism destinations. Tourism Management, 28, 14851496.

Scott, N. (2003). Tourism trends: Evolution of tourism product markets. Doctoral thesis, The University of Queensland, Queensland, Australia.

Seliger, B. (2002). Toward a more general theory of transformation. Eastern European Economics, 40(1), 36-62.

Senge, P. M. (1990). The fifth discipline: The art of practice of the learning organisation. New York: Currency Doubleday.

Sergeyev, A., \& Moscardini, A. (2006). Governance of economic transitions: A case study of Ukraine. Kybernetes, 35(1/2), 90-107.

Shelby, L. (2011). Beyond Cronbach's alpha: Considering confirmatory factor analysis and segmentation. Human Dimensions of Wildlife, 16(2), 142-148.

Shen, F., \& Cottrell, S. P. (2008). A sustainable tourism framework for monitoring residents' satisfaction with agritourism in Chongdugou Village, China. International Journal of Tourism Policy, 1(4), 368-375.

Simmons, R., Yonk, R., \& Fawson, C. (2010). Quality of life: Building an index (Final report for CREES Grant \#A19100). Logan, UT: The Center for Public Lands and Rural Economics, Utah State University.

Singh, K. (2007). Quantitative social research methods. New Delhi: Sage Publications India.

Skyttner, L. (2006). General systems theory: Problems, perspectives, practice (2nd ed.). Hackensack, NJ: World Scientific Publishing Company.

Sorenson, T., \& Epps, R. (2003). The role of tourism in the economic transformation of the central west Queensland economy. Australian Geographer, 34(1), 73-89.

Spector, E. P. (1992). Summated rating scale construction: An introduction. Menlo Park, CA: Sage.

Spitzer, D. R. (2007). Transforming performance measurement: Rethinking the way we measure and drive organisational success. New York: American Management Association (AMACOM).

StataCorp. (2009). Stata base reference manual (Vol. 11). College Station, TX: Author.

Totten, V. Y., Panacek, E. A., \& Price, D. (1999). Basics of research (Part 14): Survey research methodology: Designing the survey instrument. Air Medical Journal, 18(1), 26-34.

UCLA Academic Technology Services. (2011). What does Cronbach's alpha mean? Retrieved 17 May, 2011, from http://www.ats.ucla.edu/stat/spss/faq/alpha.html

Zahra, A. (2006). Regional tourism organisations in New Zealand from 1980 to 2005: Process of transition and change. Doctoral thesis, University of Waikato, New Zealand.

Zhang, Y., Ruhanen, L., Murphy, P., \& Cooper, C. (2004). Communities as regional destinations: A development potential index. Paper presented at the Proceedings of the Council of Australian University Tourism and Hospitality Educators Conference, Brisbane, Australia. 